\title{
Study and Proposal to Build the Maintenance Systematization for Preservation of Buildings Aiming at Long-Lived Buildings
}

\author{
Takahiro Kimura1, Hiroatsu Fukuda ${ }^{1}$, Yupeng Wang2, Tao Zhang1 \\ ${ }^{1}$ Faculty of Environmental Engineering, the University of Kitakyushu, Kitakyushu, Japan \\ ${ }^{2}$ School of Human Settlements and Civil Engineering, Xi'an Jiaotong University, Xi'an, China \\ Email: ^fukuda@kitakyu-u.ac.jp, ‘takahiro@oak.ocn.ne.jp
}

How to cite this paper: Kimura, T., Fukuda, H., Wang, Y.P. and Zhang, T. (2017) Study and Proposal to Build the Maintenance Systematization for Preservation of Buildings Aiming at Long-Lived Buildings. Journal of Building Construction and Planning Research, 5, 85-98.

https://doi.org/10.4236/jbcpr.2017.53007

Received: March 20, 2017

Accepted: August 19, 2017

Published: August 22, 2017

Copyright $\odot 2017$ by authors and Scientific Research Publishing Inc. This work is licensed under the Creative Commons Attribution International License (CC BY 4.0).

http://creativecommons.org/licenses/by/4.0/

\begin{abstract}
Systematization for the maintenance of buildings enables their supporting system to be more practical than before. This study aims to make the maintenance and the long-term repairs for the buildings to be easier. In Japan, 30-40-year-old buildings seem to have been planned and built with little thought about their future maintenances, which have made them very difficult to be repaired on a large scale. This is why effective management systems about dealing with the data should be strongly suggested. Since the Building Standard Law was amended on April 1, 2008, in Japan, the regular investigation and report for particular buildings are legally obligated every three years, thus a variety of useful data can be obtained through Kitakyushu City cases as well as former data personally obtained. With those data used usefully, systematization for the maintenance of the buildings will produce satisfactory results by building up a connection between those data and the long-term repair planning.
\end{abstract}

\section{Keywords}

Systematization for the Maintenance, Supporting System, the Client-Server System, Long-lived Buildings, Sustainable Maintenance System

\section{Introduction}

\subsection{Background}

In 2008, the authors had an opportunity to inspect condominiums regularly in Kitakyushu City, and started pursuing a building management method for lengthening the lifespan of each building. 
The regular inspection and reporting system developed in accordance with Article 12 of the Building Standards Act was revised through the enforcement on April 1, 2008. Article 12, Section 1 of the Building Standards Act stipulates that the owners (administrators if distinguished from owners) of special buildings. Designated by specific administration, agencies should make their buildings inspected by qualified inspectors and report the inspection results to the specific administrative agencies. However, it was revealed that some owners failed to fulfill this obligation to inspect buildings and report inspection results regularly, which is set forth in Article 12 of the Building Standards Act, because it was pointed out that the failure to fulfill the obligation may have caused fatal accidents at elevators and play facilities.

As of By 2014, it has been 7 years since the regular inspection and reporting system was introduced, and the number of cases of regular inspection and reporting has exceeded 100. Especially, after condominiums and apartments were inspected, some problems were identified. For example, the administrators of condominiums and apartments do not grasp the states of building-related documents or the history of repair work.

\subsection{Purposes of the Survey and Research on Buildings}

As a result of the survey, it was found that administrators do not hold sufficient basic items for maintenance and preservation, such as documents submitted for application for confirmation, certificates of confirmation, documents used for inspection at the time of completion, and certificates of inspection. In some cases, design and completion drawings were compiled, but stored poorly. Such cases are abundant, especially for buildings at the age of 20 years or older. For future buildings, it is necessary to design and build them while considering sustainable maintenance management. The authors pursue a system for reducing the cost for large-scale repair of condominiums and for making it easier.

The records of repaired parts, repairing methods, etc. in large-scale repair work are rarely held by condominium administrators or association boards. In order to maintain and manage buildings, it is essential to store records [1].

The authors' research regular inspection and reporting, and storage of new data, in order to predict future problems based on the data on condominiums, in which many occupants reside, reported in the past five years. If a system for lengthening the lifespan of each building is developed, building management will become more efficient [2].

The purpose of this study is to propose the development of a database on building states with reference to regular inspection reports and use the database for the maintenance of buildings.

\section{Survey Method}

\subsection{Surveyed Buildings}

Due to structure deterioration, a defect of evacuation equipment, a malfunction 
of construction equipment, special buildings used by a lot of unspecified people, have the risk of a grave accident or disaster, In order to prevent accidents and disasters, the Building Standards Act obliges each owner of a special building to make the building surveyed and inspected regularly by specialized engineers (qualified surveyors and inspectors) and report the results to a specific administrative agency.

Qualified inspectors, such as first-class architects, should inspect the conditions of the outer walls and some parts of buildings on a regular basis, and submit the inspection results to administrative bodies. Inspectors are obliged to inspect the sites, ground, outer parts, rooftops, roofs, inner parts, evacuation equipment, and lightning rods and so on.

There are several hundreds of medium and high-rise buildings, including condominiums and apartments owned by individuals need to be inspected in Kitakyushu City. Each building is registered in administration, and regular inspection and reporting are conducted in accordance with the Building Standards Act. Inspection reports are submitted to administrative bodies in writing, and the data of each building are inputted and managed in PCs [3]. Buildings are inspected mainly by visual check and percussion (within arm's reach). If there are any methods for utilizing inspection data based on the above-mentioned inspection and reporting system, the authors will propose them.

\subsection{Target Regions and the Age of Each Surveyed Building}

Kitakyushu City is constituted by Moji Ward, Kokura-kita Ward, Kokura-minami Ward, Tobata Ward, Yahata-higashi Ward, Yahata-nishi Ward, and Wakamatsu Ward. These wards are categorized into three regions by Kitakyushu City, and the administrators of housing complexes, etc. with 5 or more stories have the obligation to inspect their buildings and report inspection results Figure 1.

The three regions and target buildings are as follows:

1) Moji Ward, Kokura-minami Ward, and Tobata Ward

- Housing complexes and hospitals;

2) Wakamatsu Ward, Yahata-higashi Ward, and Yahata-nishi Ward

\begin{tabular}{|c|c|c|}
\hline $\begin{array}{c}\text { No. of } \\
\text { surveys }\end{array}$ & 5-year intervals & ■1 to 5 years \\
\hline 1 to 5 years & 19 & (16 to 10 years \\
\hline 6 to 10 years & 22 & 日11 to 15 years \\
\hline 11 to 15 years & 32 & Q 16 to 20 years \\
\hline 16 to 20 years & 26 &
\end{tabular}

Figure 1. Number of surveys on buildings classified by age at 5-year intervals. 
- Housing complexes, hotels, and Japanese-style inns;

3) Kokura-kita Ward

- Housing complexes, department stores, and supermarkets.

\subsection{Classification and Analysis of Survey Results}

In this study, the authors surveyed 122 housing complexes in Kitakyushu City from 2008 to 2012, and analyzed the buildings whose inspection reports had been submitted to Construction Bureau of Kitakyushu. Based on the survey data and analysis results, the authors propose the most appropriate method for producing building status charts and databases that can be used for inspecting, repairing, remodeling, renovating, and rebuilding buildings Figure 2 .

\section{Methods for Classifying and Analyzing Survey Results}

Out of building inspection items, the following 6 items were analyzed: 1) sites and grounds; 2) outer parts of buildings; 3 ) rooftops and roofs; 4) inner parts of buildings; 5) evacuation equipment; and 6) other special structures.

These 6 categories are sub-classified as shown in Figure 3 and subsequent

\begin{tabular}{|c|l|c|}
\hline Survey year & \multicolumn{1}{|c|}{ Target district } & No. of surveys \\
\hline 2008 & Moji Ward & 18 \\
\hline 2009 & $\begin{array}{l}\text { Yahata-nishi and } \\
\text { Yahata-higashi Wards }\end{array}$ & 17 \\
\hline 2010 & Kokura-kita Ward & 32 \\
\hline 2011 & Moji Ward & 30 \\
\hline 2012 & $\begin{array}{l}\text { Yahata-nishi and } \\
\text { Yahata-higashi Wards }\end{array}$ & 25 \\
\hline & Total & 122 \\
\hline
\end{tabular}

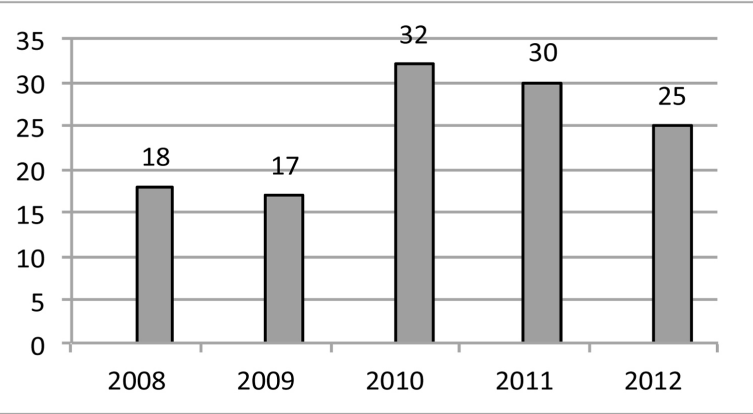

Figure 2. Number of surveyed buildings and the target district in each year.

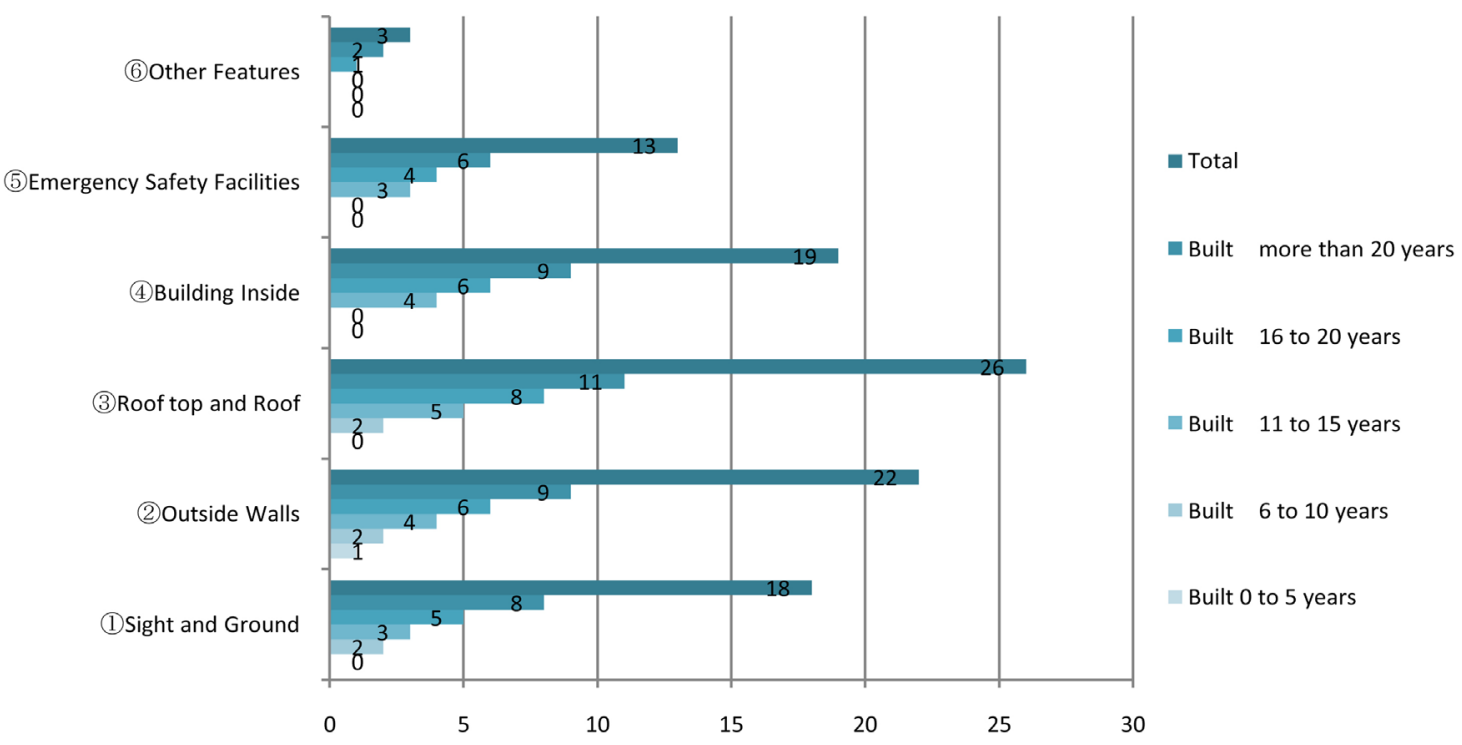

Figure 3. Survey items and the number of defective parts for each age group. 
figures. Figure 3 shows the number of defective parts of each survey item. There are many deteriorated and defective parts in the inner parts, outer parts, rooftops, roofs, and evacuation equipment in this order. Especially, buildings at the age of 20 years or older obviously have many deteriorated and defective parts.

\subsection{Characteristics and Analysis of Defective Parts in Each Survey Item}

Figure 4 shows the results of the survey of problems with sites and grounds. These survey results indicate that buildings at the age of 20 years or older have defective parts on grounds and around sites, although it is natural that older buildings have more problems.

Figure 5 shows defective parts around a site. In these photos, a gas pipe is exposed, and an asphalt pavement sagged.

In addition, the deteriorated parts of retaining walls, including cracks, were observed.

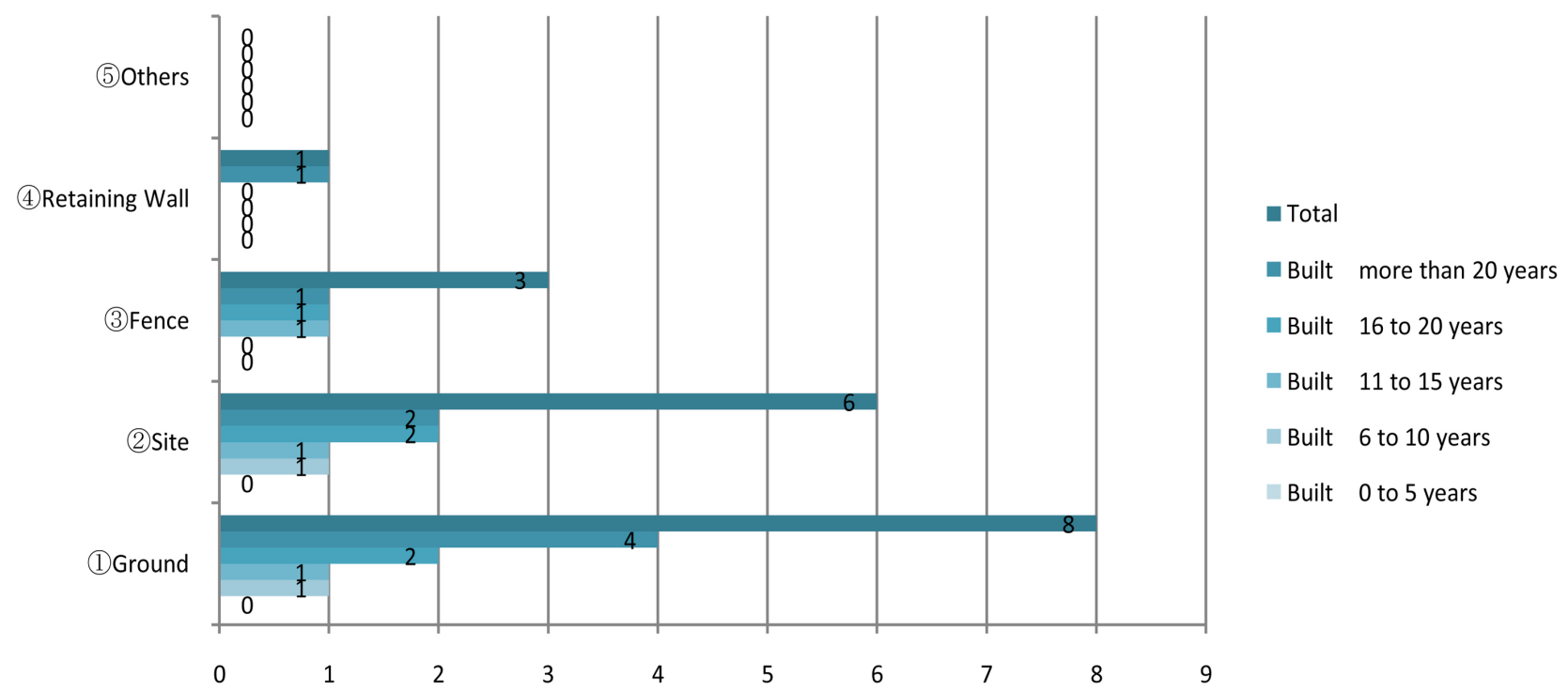

Figure 4. Defective parts on sites and grounds.
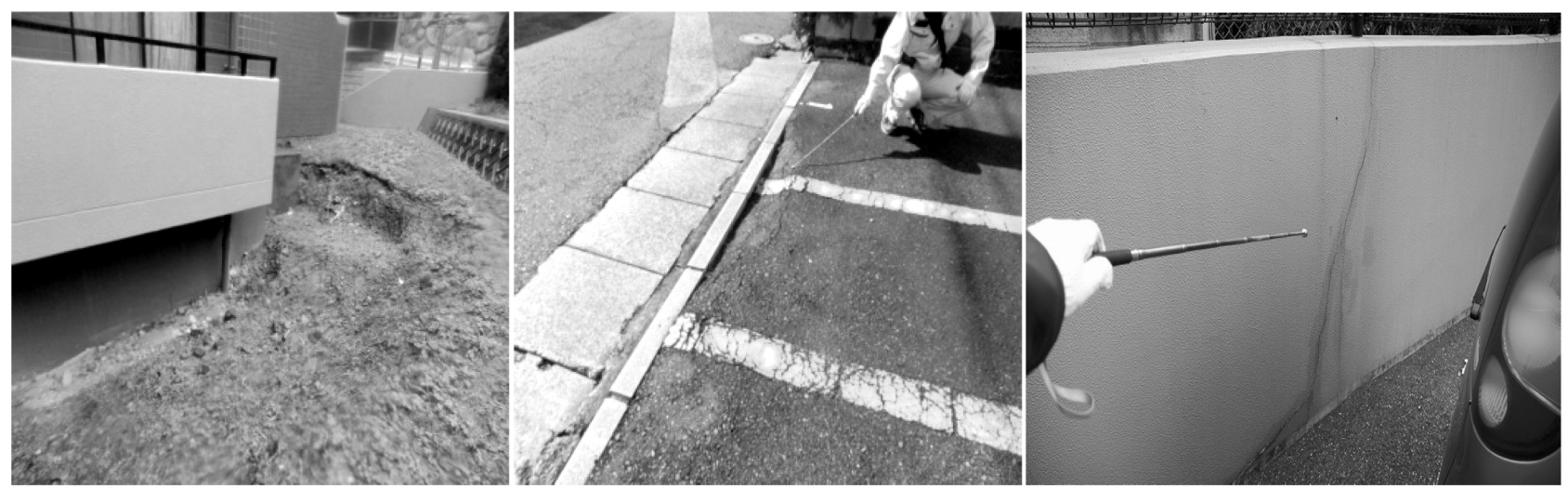

Figure 5. Photos showing defective parts on sites and grounds. 


\subsection{Situation and Analysis of Problems with the Outer Parts of Buildings}

Figure 6 shows the results of the survey of problems with the outer parts of buildings. These survey results indicate that older buildings have more defective parts in their outer walls, and buildings at the age of 15 years or younger have few defective parts in their foundations or grounds.

On April 1, 2008, the Building Standards Act was amended, and it stipulated that the regular inspection report on each specific building should include percussion results. Regular percussion inspection had been conducted before April 1, 2008, but the Building Standards Act did not set forth a penalty for the failure to conduct percussion inspection. The new Building Standards Act specifies additional inspection in the 10th year after construction and outer wall repair, in addition to regular percussion inspection.

The latest data should be saved in servers for recording the results of outer wall inspection, in addition to reporting. By accessing the servers, it would be possible to solve the questions regarding maintenance management for condominium administrators.

The current Building Standards Act stipulates that the outer walls of the following buildings should undergo percussion inspection:

1) Buildings whose abnormalities have been discovered by regular partial percussion or visual inspection;

2) Buildings at the age of 10 years or older;

3) Buildings whose outer walls were repaired 10 years ago;

4) Buildings for which percussion inspection was conducted 10 or more years ago and the results of the latest percussion inspection indicates danger for pedestrians.

Before the amendment to the Building Standards Act, it was stipulated that if any abnormality is detected through partial percussion or visual inspection, the inspector should advise the building owner to conduct "detailed inspection".

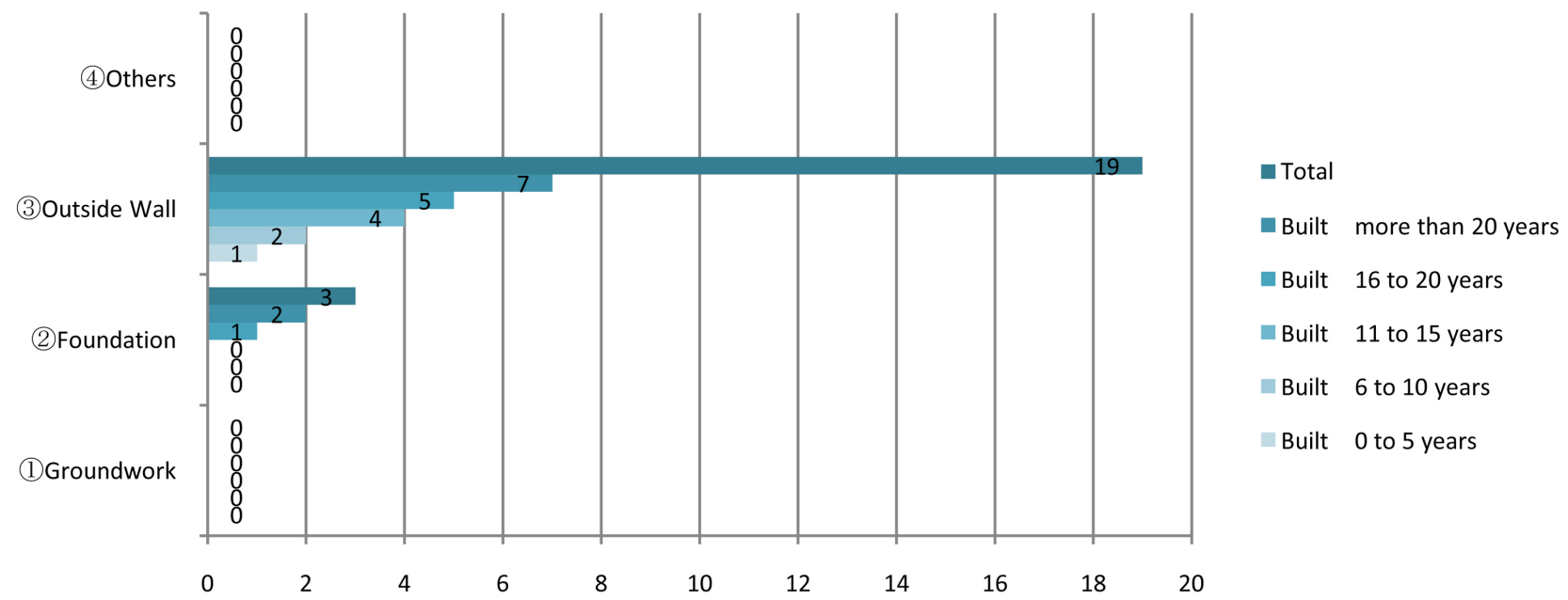

Figure 6. Defective parts on the outer parts of buildings. 
After the amendment to the Building Standards Act, it was stipulated that if any abnormality is discovered through partial percussion or visual inspection, the inspector should continue the percussion inspection of the whole surfaces of outer walls [4]. In addition, it is necessary to carry out the percussion inspection of the whole surfaces of outer walls for the buildings 10 years after the construction and also 10 years after the repair of outer walls Figure 7.

\subsection{Situation and Analysis of Problems with Rooftops and Roofs}

Figure 8 shows the results of the survey on problems with the outer parts of buildings. The results indicate that older buildings have more deteriorated rooftops.

Figure 9 shows the photos of the deteriorated water-proof and protective mortar parts of rooftops.

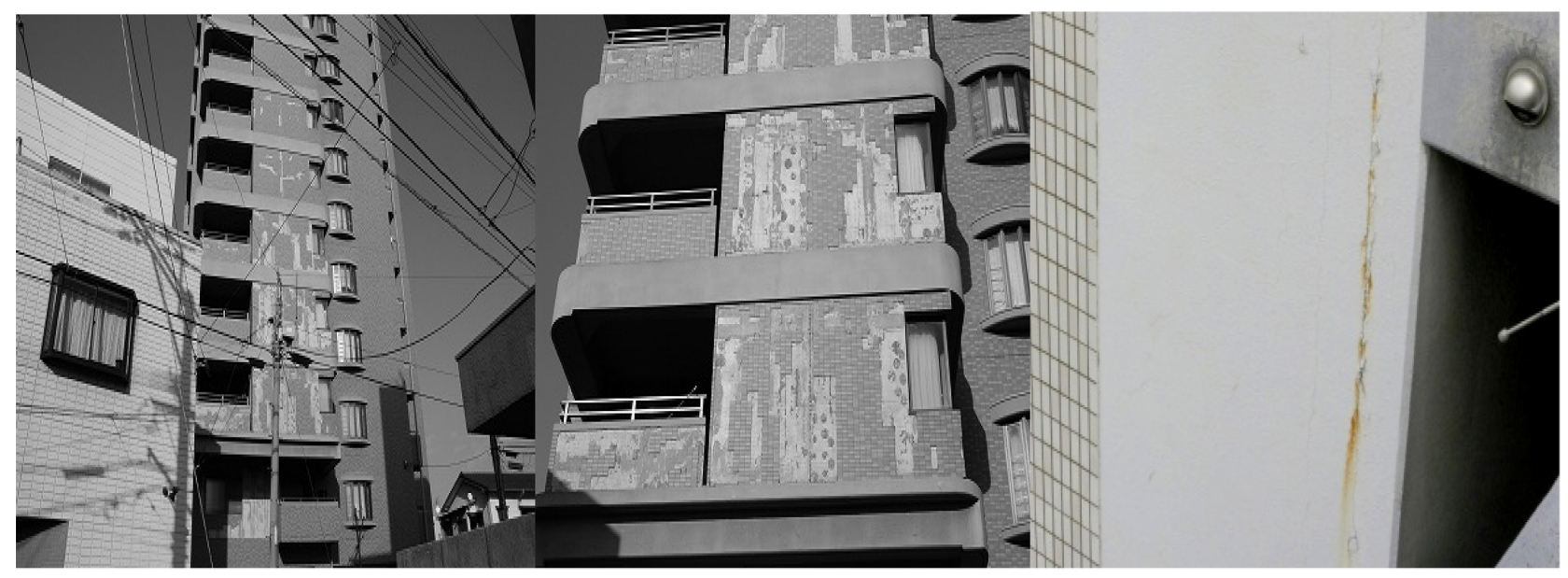

Figure 7. The defective parts (concrete cracks) of the outer walls of buildings.

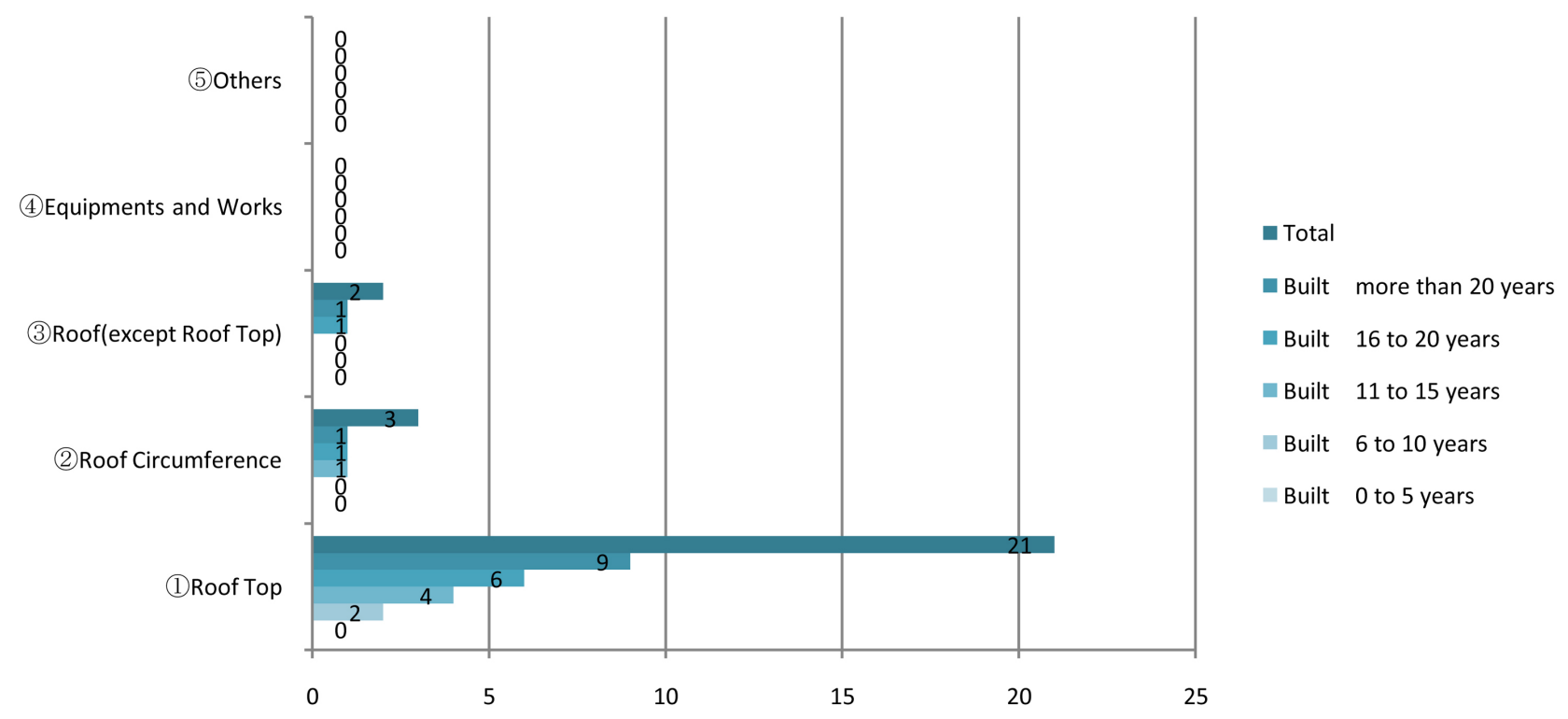

Figure 8. Defective parts on rooftops and roofs. 


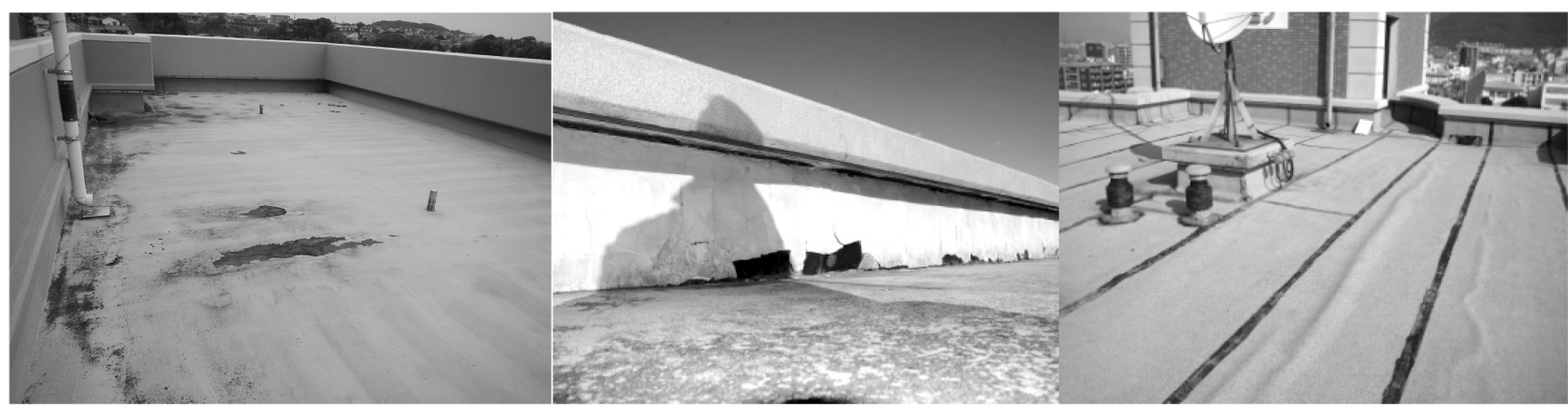

Figure 9. Photos showing defective parts on a rooftop and a roof.

\subsection{Situation and Analysis of Problems with the Inner Parts of Buildings}

Figure 10 shows the results of the survey on problems with the inner parts of buildings. From these results, it was found that defective parts exist mainly in fire-proof areas and inner walls, and older buildings have more defective parts. As for the fire-proof area among the sub-items of the survey, elevator doors had been recognized as fire-proof doors with the smoke insulation function in the Building Standards Act (Announcement No. 1111 of Construction Ministry in 1981), but this announcement became invalid through the amendment to the Building Standards Act in Jun. 2000.

In order to prevent smoke entering other floors at the time of fire, it becomes necessary to install fire-proof equipment with smoke insulation function according to the revision to the provisions for the smoke insulation function of elevator doors in 2002, Accordingly, the elevator doors of the buildings constructed in or before 2002 do not comply with the new provisions, and these doors are excluded from the results of this survey.

\subsection{Situation and Analysis of Problems with Evacuation Equipment, Etc.}

Figure 11 shows the results of the survey on problems with evacuation equipment and Figure 12 shows some of photos taken for the survey. These survey results indicate that evacuation stairs and passages have many defective parts. In many cases, daily necessities and bicycles are left and the outdoor devices of air-conditioners are set on evacuation passages, and fire-proof doors for evacuation stairs cannot be closed fully.

The second-year provisions of the "Law for the Partial Amendment to the Building Standards Act", which was promulgated on June 12, 1998, were enforced on June 1, 2002.

In accordance with Article 36 of the Building Standards Act and Articles 23 and 25 of the Order for Enforcement, the method for calculating stairway width and the standards for setting railings have been changed.

Previously, there were no regulations for railings when calculating stairway width, but through this amendment, it became possible to calculate stairway 


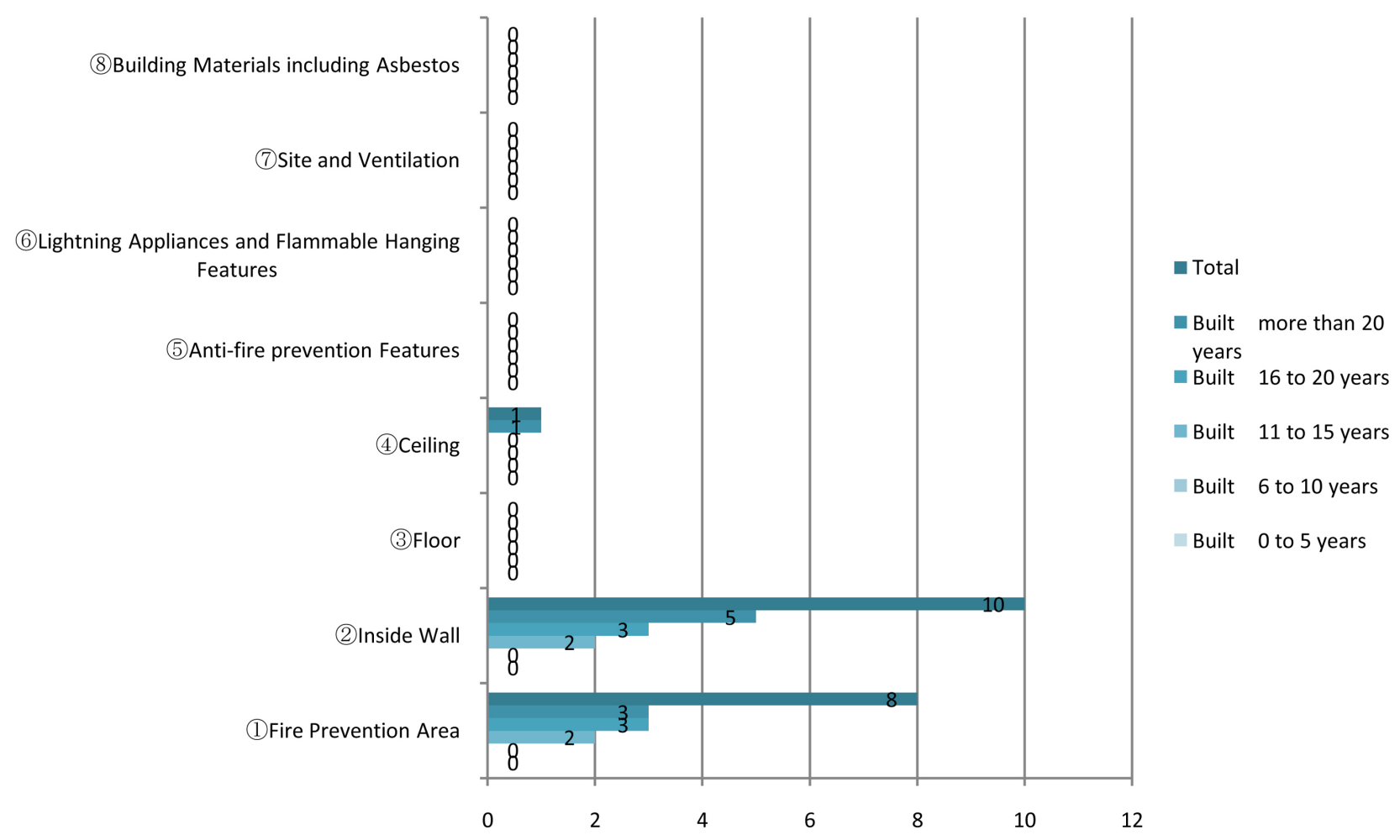

Figure 10. Defective parts on a rooftop and a roof.

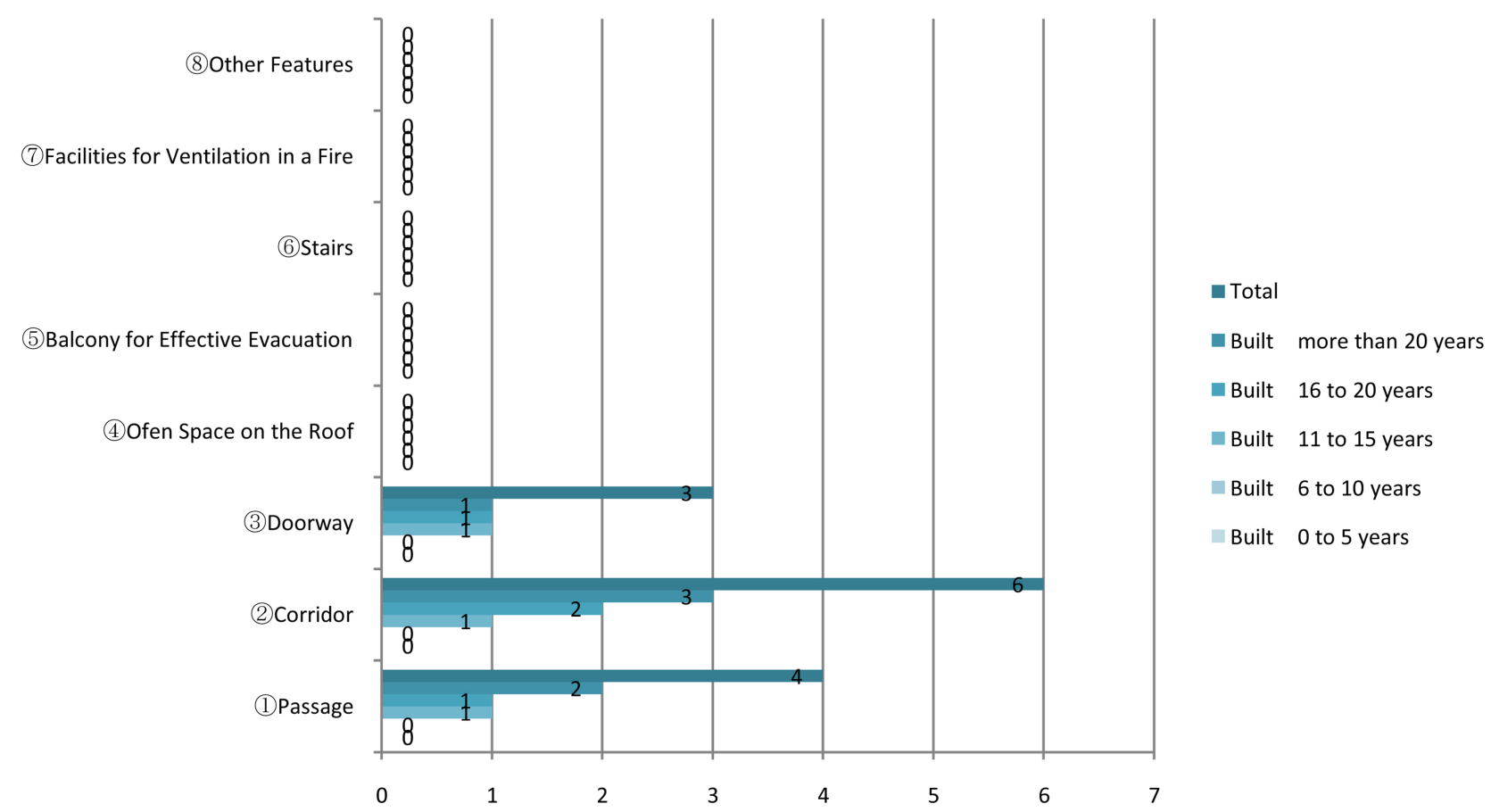

Figure 11. Defective parts on evacuation equipment, etc.

width while assuming that a railing width of up to $10 \mathrm{~cm}$ does not exist. Previously, the setting of railings was not mandatory when there were sidewalls or the like in stairways and landings, but through this amendment, it became ne- 

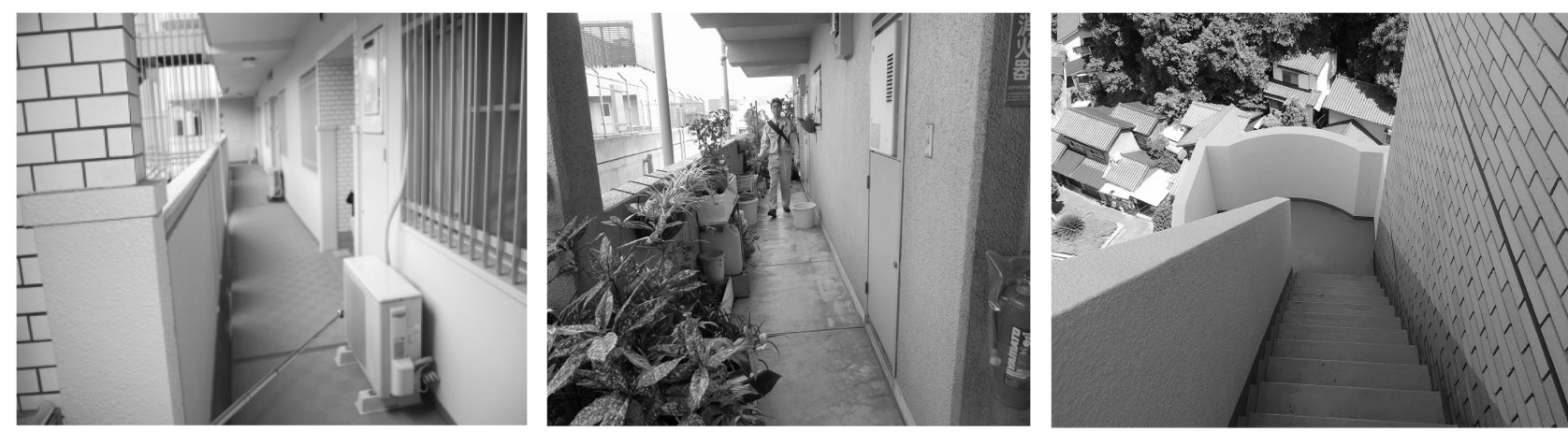

Figure 12. Photos showing defective parts on evacuation equipment, etc.

cessary to set a railing at least at one side, and build sidewalls or the like at both sides on the second floor.

The difference between the old and new laws is the application condition for actual construction work. (See the webpage regarding the amendment to the Building Standards Act.)

The stairway railings of the buildings constructed in or before May 1998 do not comply with the amended law. Stairway railings are set in $90 \%$ of the surveyed buildings constructed in or after June 1998.

\subsection{Situation and Analysis of Problems with Other Special Structures, Etc.}

Figure 13 shows the results of the survey on problems with other special structures, etc.

The survey results indicate that there are a few defective parts in the buildings at the age of 15 years or older, such as corroded parts of lightning rod equipment and defective parts of mechanical parking garages, as shown in Figure 14.

\section{Proposal for the Systematization of Building Management}

\subsection{Current Status of Building Management}

By producing building records for maintenance management based on the regular inspection and reporting system and using data for lengthening the lifespan

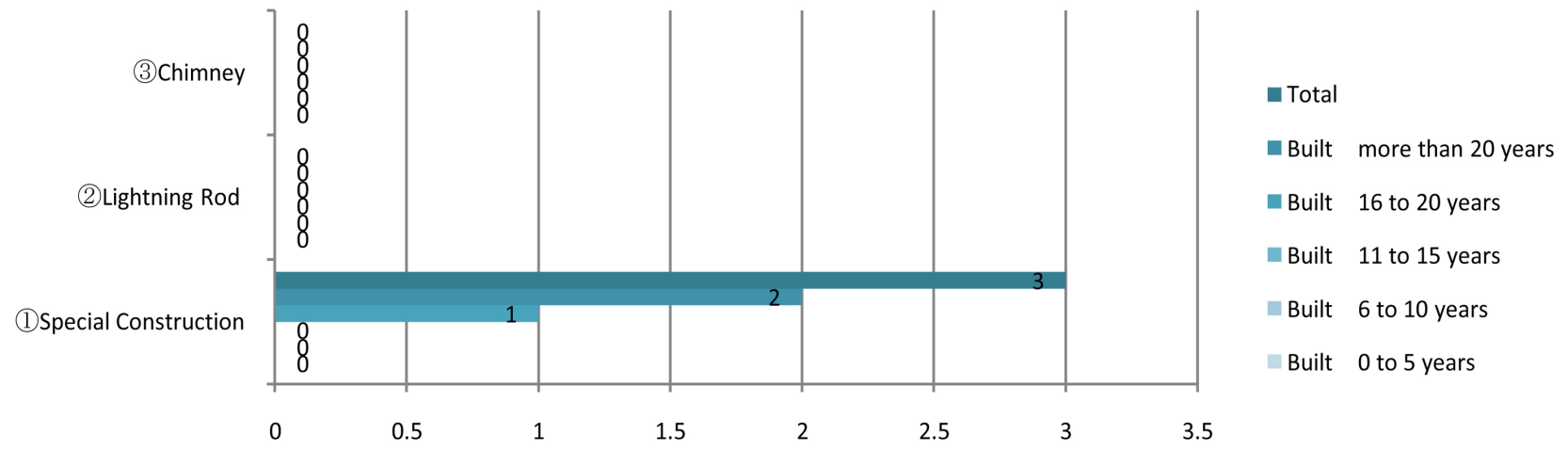

Figure 13. Defective parts on other special structures, etc. 


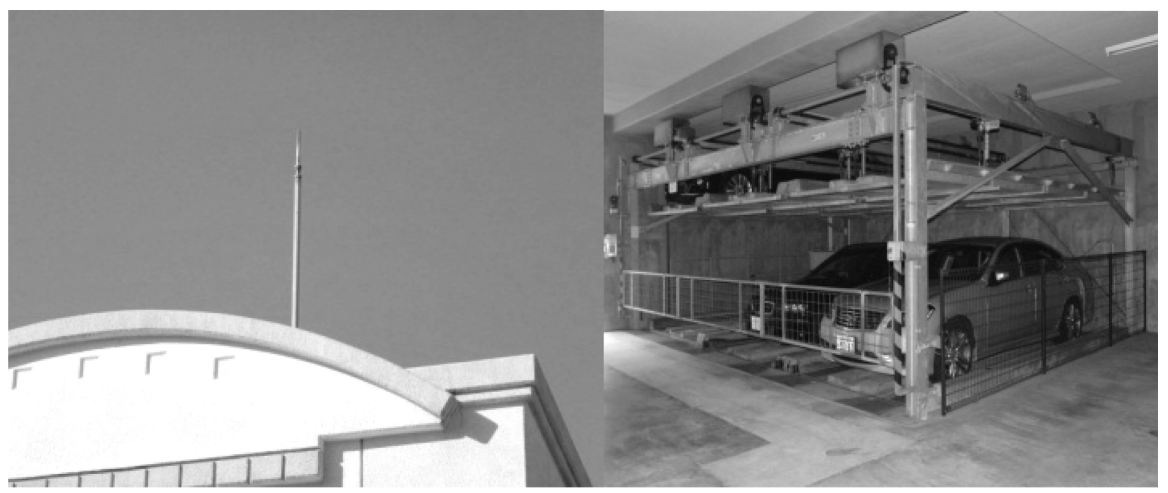

Figure 14. Photos showing the corroded parts of lightning rods and mechanical parking garages.

of each building as shown in Figure 16, it would be possible to achieve sustainable maintenance management. There are some obstacles and problems to be overcome. It is unclear how much the inspection reports submitted to administrative bodies have been digitalized. The summaries of inspection reports have been recorded, but the records are rarely used for the maintenance of buildings. For inadequate buildings, administrative bodies give instructions, supervision, etc., but for other buildings, building owners just submit reports, and documents are not digitalized, and they are not always utilized. In addition, the items inspected by regular inspection reporters are not sufficient, and so more detailed items are required for producing building diagnosis records. For example, in the survey on outer walls, it is necessary to check and record the ratio of defective parts on outer walls at all sides of each building, the bulging, cracks, peeling, and loss of outer wall tiles, etc.

Figure 15 shows the graph of the characteristics of defective parts on outer wall tiles. It is considered that these survey results varies according to the conditions of land, the structures, shapes, number of stories, etc. of buildings. The authors summarized the results of the survey on 122 buildings in the past 5 years.

These results indicate that the outer wall tiles on the south and west sides have many defective parts, especially bulging tiles. Therefore, it is necessary to subclassify survey items and define necessary items as data.

On June 17, 2008, the condominium policy division, the urban construction section, the housing bureau, Ministry of Land, Infrastructure, Transport and Tourism issued a template for long-term repair plans, the guidelines for producing a long-term repair plan, and comments. Then, it became necessary to produce an appropriate long-term repair plan for conducting timely and appropriate repair work according to the deterioration of each building, and determine the amount of reserve for large-scale repair based on the plan. It would be effective to interconnect long-term repair plans and regular inspection and reporting forms.

\subsection{Systematization of the Maintenance Management}

Figure 16 shows a schematic diagram of the systematization of the maintenance 


\begin{tabular}{|c|c|c|c|c|}
\hline $\begin{array}{c}\text { No. of defective } \\
\text { parts } \\
\text { Age }\end{array}$ & East side & West side & South side & North side \\
\hline Bulging of tiles & 22 & 43 & 51 & 13 \\
\hline $\begin{array}{c}\text { Cracks on outer } \\
\text { wall tiles }\end{array}$ & 5 & 10 & 15 & 6 \\
\hline $\begin{array}{c}\text { Peeling and loss } \\
\text { of tiles }\end{array}$ & 3 & 6 & 8 & 2 \\
\hline Total & 30 & 59 & 74 & 21 \\
\hline
\end{tabular}

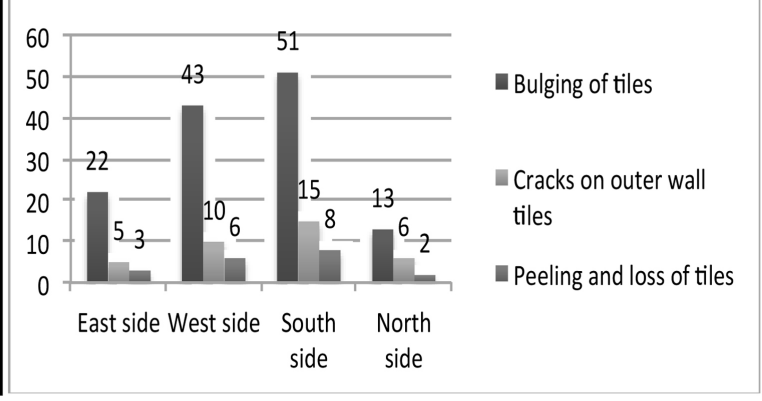

Figure 15. Defective parts of outer wall tiles.

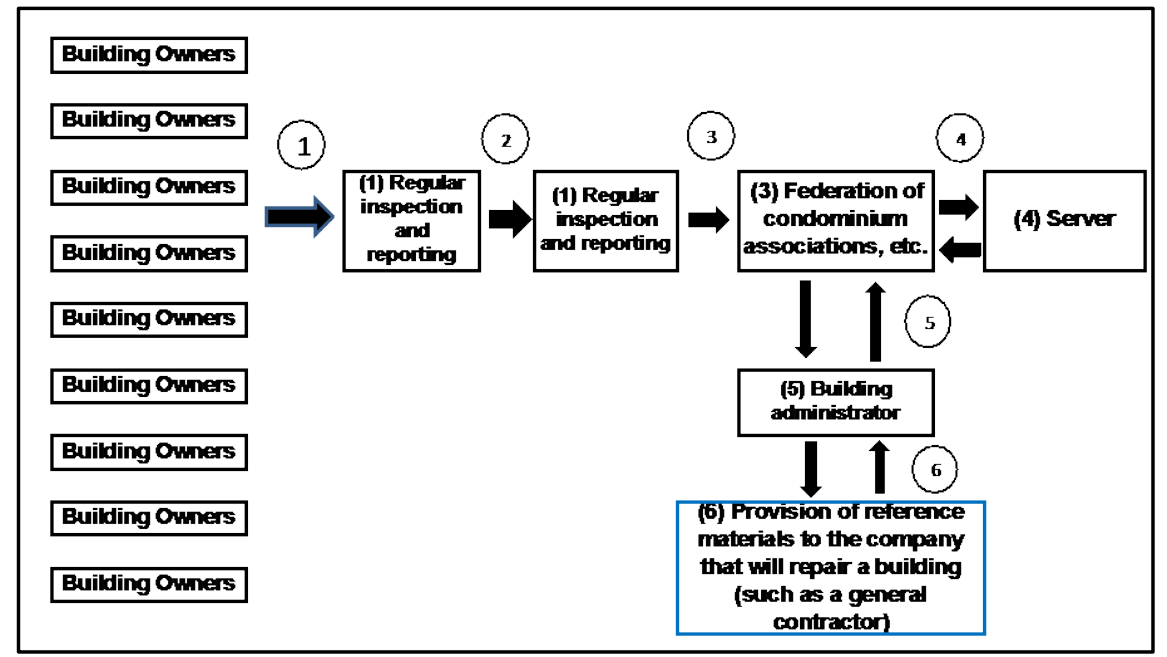

Figure 16. Schematic diagram of the systematization of the maintenance management of buildings.

management of buildings.

1) A Building administrator should request a qualified inspector to inspect his/her building.

2) A regular inspection report is submitted to an administrative body.

In the current system, the procedures end here. The following procedures (3) to (6) are proposed for systematizing the maintenance management of buildings.

3) The documents obtained by the administrative body should be put together by the federation of condominium associations or the like, and stored in a server.

4) The data are saved and stored in a server or the like.

5) Each building manager can retrieve the data on his/her own building only by using his/her ID or password.

It is possible to provide several construction companies with the data for estimating the cost for remolding or large-scale repair. The data can be used as fair, reliable reference materials for estimation [5].

If the above processes are established, it will be possible to store and update the basic data and reference materials for the maintenance management of buildings for a long period of time. 
In order to solve the problems with compiled design documents owned by many building administrators, designers and constructors need to provide building administrators with at least digitized design and completion drawings (in the PDF format) as the documents describing important items [5]. If these documents are stored, it will be possible to utilize them for producing regular inspection reports and grasp the states of buildings more easily.

Furthermore, if developers can provide condominium associations, which own completed buildings, with some estimates for construction costs submitted by general contractors to developers at the time of the conclusion of contracts for new construction, they will be easily utilized for selecting construction companies for large-scale renovation or repair in the future [6].

\section{Conclusion}

For lengthening the lifespan of each building, by systematizing the maintenance management of buildings and developing a supportive system, it will become able to clearly grasp the flow of building inspection and diagnosis, the understanding of building states, the analysis of defective parts, the discussion on solutions, and repair work, and then it will become easier to maintain buildings and produce long-term repair plans. Furthermore, it will be possible to secure the fairness of the estimates for repair work submitted by several general contractors and follow the standards of construction. As it is difficult to avoid the deterioration of buildings, it is essential to establish a system for making buildings sustainable and grasping the information on maintenance management for a long period of time. Another proposal is to record and store the inspection documents digitized from written documents by utilizing the GIS (geographical information system), which would make it easier to manage three-dimensional data and make it possible to retrieve data on condominiums in a moment [7]. In order to lengthen the lifespan of each building, it is vital for building owners to hold the data of regular inspection and the history of design, construction, and maintenance. This would enable building administrators and constructors to obtain data and check the records of buildings easily, and then take appropriate measures. Especially, it would be possible to propose the maintenance methods by municipalities and the private sector, and develop a system for them [8]. It is expected that the GIS operated by administrative bodies will be utilized for future systems.

\section{Acknowledgements}

I'm deeply grateful to Dr. Eng, Prof. Hiroatsu Fukuda, Kitakyushu University, Japan, Dr. Eng, Prof. Yupeng Wang, Xi'an Jiaotong University, China, and Dr. Eng, Tao Zhang, Kitakyushu University, Japan for their constructive comments and warm encouragement, while writing this thesis. Advice and support given by them has been a great help.

\section{References}

[1] Ryosuke, F. and Tetsukazu, A. (2009) About Difference of Maintenance Cost of In- 
dividual Building of the Complex of Condominiums-Case Study of the Extensive Renovations of Two Complexes of Condominiums in Metropolitan Area. Journal of Architecture and Planning (Transactions of AI), 74, 223-231. https://doi.org/10.3130/aija.74.223

[2] Hiroko, S. (2002) A Study on Number of Units of Condominium for Management of Living Environment by Homeowners' Association. Journal of Architecture and Planning (Transactions of AI), 533, 269-274.

[3] Joji, A. and Nozomu, K. (2007) Research on Regional Variance of Dwelling Unit Size and It'S Background / Focusing on Comparison between Heavy Snow Area and South Sea Area. Journal of Architecture and Planning (Transactions of AI), 622, 181-186.

[4] Yue, L., Shuzo, F. and Takashi, K. (2007) Study on Quality Assurance in Chinese Construction Project: A Comparative Study on Construction Project Management between China and Japan Part 4. Journal of Architecture and Planning (Transactions of AIJ), 622, 175-180.

[5] Toru, O. and Kazuyoshi, E. (2006) A Study on the Cost Management of Small Scale Building Works by Homebuilders. Journal of Architecture and Planning (Transactions of AI), 610, 147-152.

[6] Yukio, K. and Mamoru, S. (2003) Life Time Estimation of Office Buildings Based on General Contractors Construction Records. Journal of Architecture and Planning ( Transactions of AIJ), 565, 317-322.

[7] Shin, M. and Norie, K. (2007) Study on Dwellers' Consciousness on Agreement for Renovation of Multi-Family Dwellings. Journal of Architecture and Planning (Transactions of AI), 72, 141-147.

[8] Kenji, H., Daiki, I., Sangjun, Y., Hiroki, T., Yukio, K. and Masato, A. (2011) Long Life Repair Methods for Existing Facilities: Effectiveness of External Insulation Finishing System for Long Life Facilities. Journal of Architecture and Planning (Transactions of AI), 76, 169-177. https://doi.org/10.3130/aija.76.169

Scientific Research Publishing

\section{Submit or recommend next manuscript to SCIRP and we will provide best service for you:}

Accepting pre-submission inquiries through Email, Facebook, LinkedIn, Twitter, etc. A wide selection of journals (inclusive of 9 subjects, more than 200 journals)

Providing 24-hour high-quality service

User-friendly online submission system

Fair and swift peer-review system

Efficient typesetting and proofreading procedure

Display of the result of downloads and visits, as well as the number of cited articles

Maximum dissemination of your research work

Submit your manuscript at: http://papersubmission.scirp.org/

Or contact jbcpr@scirp.org 